\title{
Potencial de utilização do dietholate como protetor de clomazone em feijoeiro comum $^{1}$
}

\author{
Potential use of dietholate as a safener for clomazone in common beans
}

\author{
Hudson Kagueyama Takano ${ }^{2}$; Rubem Silvério de Oliveira Jr. ${ }^{3}$; Jamil Constantin ${ }^{3}$; Antonio \\ Mendes de Oliveira Neto ${ }^{4}$; Guilherme Braga Pereira Braz ${ }^{5}$; Hugo Almeida Dan ${ }^{6}$; Naiara Guerra \\ Fabiano Aparecido Rios 5
}

Resumo - Protetores de plantas são produtos químicos usados com a finalidade de aumentar a seletividade de herbicidas. O objetivo deste trabalho foi verificar os efeitos da utilização de dietholathe como protetor para o herbicida clomazone aplicado em pré-emergência na cultura do feijoeiro. Os tratamentos foram arranjados em esquema fatorial $2 \times 5 \times 6$, em que o primeiro fator foi constituído de dois tratamentos herbicidas (sem e com clomazone a $750 \mathrm{~g} \mathrm{ha}^{-1}$ ); o segundo, de doses de dietholate $(0,125,250,375$ e $500 \mathrm{~g}$ i.a. por $100 \mathrm{~kg}$ de semente); e o terceiro fator de diferentes cultivares de feijoeiro (Diamante Negro, Ouro Branco, Jalo Precoce, BRS Pérola, BRS Pontal e BRS Radiante). O dietholate não apresentou potencial para proteger as plantas de feijoeiro dos efeitos fitotóxicos do herbicida clomazone, aumentando a sensibilidade das plantas à aplicação do herbicida.

Palavras-chaves: seletividade, intoxicação, pré-emergência, Phaseolus vulgaris

Abstract - Safeners are chemicals applied to crops, usually by seed treatment, to improve their tolerance to herbicides. The objective of this research was to evaluate the potential use of dietholate as a safener for pre-emergence applications of clomazone in common beans. Treatments were arranged in a factorial combination $2 \times 5 \times 6$ composed by two herbicide treatments (without or with clomazone at $750 \mathrm{~g} \mathrm{ha}^{-1}$ ), five doses of dietholate $(0,125,250,375$ and 500 g. a.i. per $100 \mathrm{~kg}$ of seeds), and six cultivars (Diamante Negro, Ouro Branco, Jalo Precoce, BRS Pérola, BRS Pontal and BRS Radiante). Dietholate only did not exhibit potential to protect common bean from injuries caused by clomazone, but also increase crop sensibility to the herbicide.

Keywords: selectivity, crop injury, pre-emergence, Phaseolus vulgaris

\footnotetext{
${ }^{1}$ Recebido para publicação em 07/11/2012 e aceito em 20/12/2012.

2 Acadêmico do curso de Agronomia da Universidade Estadual de Maringá (UEM/NAPD), Av. Colombo 5790, 87020-900, Maringá, PR. Email: <hudsontakano@gmail.com>. (Autor para correspondência).

${ }^{3}$ Professores do Departamento de Agronomia da Universidade Estadual de Maringá (UEM/NAPD).

${ }^{4}$ Professor da Faculdade Integrado de Campo Mourão, Campo Mourão, PR, Brasil.

${ }^{5}$ Doutorandos do Programa de Pós-Graduação em Agronomia da Universidade Estadual de Maringá (UEM/NAPD).

${ }^{6}$ Professor do Instituto Federal de Rondônia, Colorado do Oeste, RO, Brasil.
} 


\section{Introdução}

A interferência causada pelas plantas daninhas é um dos fatores mais limitantes na produtividade do feijoeiro. Além disso, por tratar-se de uma planta de ciclo vegetativo relativamente curto, torna-se bastante sensível à competição, sobretudo nos estádios iniciais de desenvolvimento (Cobucci et al., 1999), podendo reduzir o rendimento de grãos em até 71\% (Koslowski et al., 2002).

O manejo químico de plantas daninhas pode ser uma ferramenta eficaz no controle das plantas daninhas visando à redução de perdas da produtividade. Entretanto, existem poucas opções de herbicidas seletivos em préemergência no feijoeiro.

O clomazone é um herbicida pertencente ao grupo químico das isoxazolinonas, indicado para aplicações em pré-emergência no controle de gramíneas anuais e de algumas folhas largas; possui atividade residual no solo, impedindo a emergência das espécies que lhe são suscetíveis, por 100 a 120 dias (Karam et al., 2010). Em um estudo sobre os efeitos do clomazone em plantas de feijoeiro, Takano et al. (2012) verificaram apenas $8,75 \%$ de fitointoxicação aos 28 DAE provocada pela utilização de $900 \mathrm{~g} \mathrm{ha}^{-1}$ deste herbicida na cultivar BRS Pontal. Por outro lado, utilizando a mesma dose, estes autores constataram $58,75 \%$ de fitointoxicação na cultivar BRS Radiante nesta mesma ocasião, evidenciando a baixa tolerância de algumas cultivares ao clomazone. Diferenças pronunciadas na sensibilidade de cultivares a um determinado herbicida dificultam sua utilização, uma vez que indicam seletividade marginal para a cultura.

A seletividade deste herbicida para as culturas pode ser aumentada por meio do uso de protetores de plantas, que são produtos químicos usados com a finalidade de aumentar a tolerância da cultura à intoxicação imposta pelo herbicida, sem reduzir a eficiência no controle das plantas daninhas (Oliveira Jr; Inoue, 2011). Os protetores existentes no mercado são utilizados principalmente na proteção das culturas do sorgo, milho, arroz, fumo, algodão e cereais de inverno, contra injúrias dos herbicidas dos grupos tiocarbamatos, cloroacetanilidas, cloroacetamidas, sulfoniluréias e ariloxifenoxipropionatos e isoxazolidinonas (Galon et al., 2011).

No caso do feijoeiro, o uso dessas substâncias protetoras pode facilitar o controle de plantas daninhas dicotiledôneas, pois segundo Galon et al. (2011) os protetores são ideais para o controle de plantas daninhas com características morfofisiológicas semelhantes às das culturas que infestam. A utilização do protetor dietholate no tratamento de sementes de arroz irrigado, visando a proteger a cultura do efeito fitotóxico provocado pelo herbicida clomazone promoveu resultados positivos (Mistura et al., 2008; Sanchotene et al., 2010), mesmo quando aplicado em baixas dosagens. No entanto, para o dietholate tem se observado que a germinação, a emergência e o desenvolvimento da parte aérea, da raiz e do coleóptilo do arroz podem ser comprometidas, causando até $30 \%$ de redução do estande da cultura (Mistura et al., 2008).

Sendo assim, o objetivo deste trabalho foi avaliar os efeitos da utilização de dietholathe como protetor do herbicida clomazone aplicado em pré-emergência de diferentes cultivares de feijoeiro comum.

\section{Material e Métodos}

$\mathrm{O}$ experimento foi conduzido em casade-vegetação no Centro de Treinamento em Irrigação (CTI), que pertence ao campus central da Universidade Estadual de Maringá (UEM), localizada em Maringá - PR. O período de condução dos ensaios foi de 16/09/2011 a 22/10/2011.

Os tratamentos foram arranjados em esquema fatorial $2 \times 5 \times 6$, em que primeiro 
fator foi constituído de dois tratamentos herbicidas (sem e com clomazone a $750 \mathrm{~g}$ i.a. $\left.\mathrm{ha}^{-1}\right)$; o segundo, de doses crescentes de dietholate $(0,125,250,375$ e $500 \mathrm{~g}$ i.a. por 100 $\mathrm{kg}$ de sementes); e o terceiro, de diferentes cultivares de feijoeiro (Diamante Negro, Ouro Branco, Jalo Precoce, BRS Pérola, BRS Pontal e BRS Radiante). O delineamento experimental utilizado foi inteiramente casualizado, com cinco repetições.

As unidades experimentais eram compostas por vasos de $3 \mathrm{dm}^{3}$, os quais foram preenchidos com solo que apresentava valores de $\mathrm{pH}$ em água de 5,90; 3,68 $\mathrm{cmol}_{\mathrm{c}}$ de $\mathrm{H}^{+}+$ $\mathrm{Al}^{+3} \mathrm{dm}^{-3}$ de solo; $3,17 \mathrm{cmol}_{\mathrm{c}} \mathrm{dm}^{-3} \mathrm{de} \mathrm{Ca}^{+2}$; $0,67 \mathrm{cmol}_{\mathrm{c}} \mathrm{dm}^{-3}$ de $\mathrm{Mg}^{+2} ; 0,61 \mathrm{cmol}_{\mathrm{c}} \mathrm{dm}^{-3}$ de $\mathrm{K}^{+} ; 47,60 \mathrm{mg} \mathrm{dm}^{-3}$ de P; 11,89 $\mathrm{g} \mathrm{dm}^{-3}$ de C; $640 \mathrm{~g} \mathrm{~kg}^{-1}$ de areia grossa; $50 \mathrm{~g} \mathrm{~kg}^{-1}$ de areia fina; $20 \mathrm{~g} \mathrm{~kg}^{-1}$ de silte e $290 \mathrm{~g} \mathrm{~kg}^{-1}$ de argila. As sementes de feijoeiro com suas respectivas doses de dietholate (0,0-diethyl 0-phenyl phosphorothioate) foram agitadas dentro de sacos plásticos com capacidade de cinco litros, a fim de se obter um tratamento de sementes homogêneo. Em seguida foram semeadas cinco sementes de feijoeiro por vaso, a uma profundidade de 2 a $3 \mathrm{~cm}$, sendo os vasos em seguida umedecidos.

Para a aplicação de clomazone foi utilizado um pulverizador costal de pressão constante por $\mathrm{CO}_{2}$, equipado com barra munida de três pontas tipo leque XR-110.02, espaçadas de $50 \mathrm{~cm}$ entre si, sob pressão de $2,0 \mathrm{kgf} \mathrm{cm}^{-2}$. Estas condições de aplicação proporcionaram o equivalente a $200 \mathrm{~L} \mathrm{ha}^{-1}$ de calda. No momento da aplicação, as condições climáticas encontradas foram: Temperatura de $27,0^{\circ} \mathrm{C}$; Umidade relativa do ar de $70,0 \%$ e velocidade do vento de $1,2 \mathrm{~km} \mathrm{~h}^{-1}$.

Foram realizadas avaliações de índice de velocidade de emergência (IVE) até os 5 dias após o início da emergência (DAE) e altura das plantas e teor de clorofila nas folhas aos 7 e 21 DAE. Também foram mensurados a massa seca foliar e massa seca do caule aos 21 DAE. O índice de velocidade de emergência foi conduzido a partir da semeadura em vasos e as plântulas emergidas foram contadas diariamente entre o início da emergência e momento de estabilização numérica das contagens (5 DAE) conforme a metodologia proposta por Maguire (1962). Na medição da altura considerou-se a base do solo até o meristema apical da planta. A determinação do teor de clorofila foi realizada nas últimas folhas expandidas por meio de um clorofilômetro portátil, modelo SPAD-502 (Konica Minolta, Japão). A massa seca foliar e do caule foram obtidas pelo corte das plantas na altura do solo e posterior secagem das partes das plantas em estufa de circulação forçada de ar, na qual as amostras permaneceram durante 72 horas à temperatura constante de $65^{\circ} \mathrm{C}$.

Os dados foram submetidos à análise de variância pelo teste $F$, e quando se verificou efeito significativo para alguma variávelresposta, foram ajustados modelos lineares de regressão para as variáveis-resposta quantitativas através do programa estatístico SISVAR.

\section{Resultados e Discussão}

Houve interação significativa entre a aplicação de clomazone, o tratamento de sementes com dietholate e as cultivares de feijoeiro para todas as variáveis-resposta analisadas, exceto para o teor de clorofila e para a massa seca de caule aos 21 DAA.

A utilização de dietholate no tratamento de sementes afetou o índice de velocidade de emergência (IVE) de todas as cultivares de feijoeiro à medida que a dose deste protetor foi aumentando (Figura 1). Apesar de o dietholate ter afetado o IVE das sementes de feijoeiro, não foi constatada redução na porcentagem de plantas emergida, visto que, ao final desta avaliação todos os tratamentos encontravam-se com o número semelhante de plantas por vaso.

Nos tratamentos em que o dietholate foi utilizado em conjunto com a aplicação do clomazone, foi constatada uma redução no IVE 
ainda maior. Isto ocorreu, possivelmente, porque as sementes de feijão possuem algum grau de sensibilidade ao dietholate e ao clomazone, a qual contribui para a redução do seu vigor. Segundo Lima et al. (2005) o IVE é um dos parâmetros utilizados para se estimar o vigor das sementes, sendo assim, quanto mais rápido é a emergência dessas sementes maior o seu vigor.
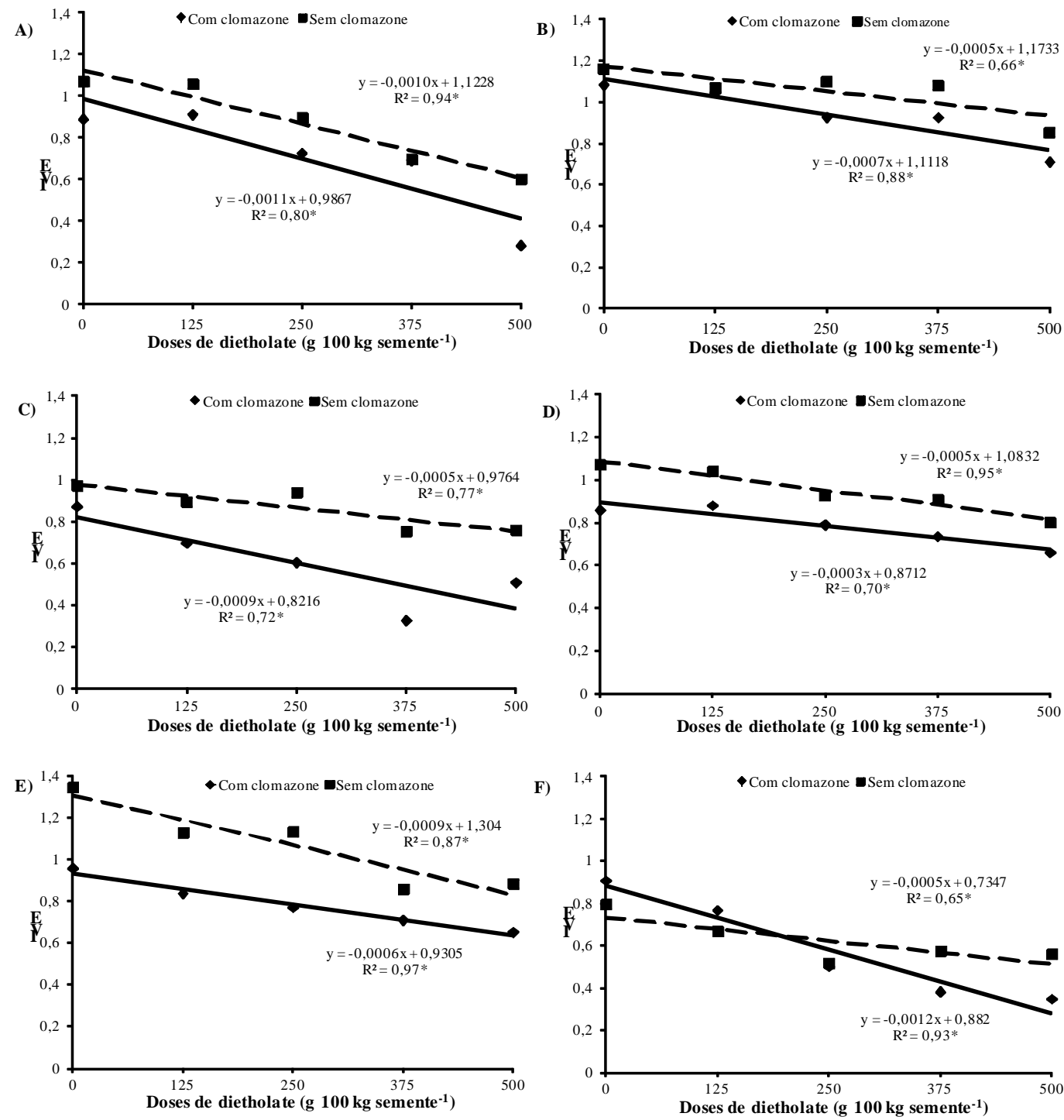

Figura 1. Índice de velocidade de emergência (IVE) de plantas de feijoeiro submetidas a doses crescentes de dietholate, com e sem aplicação de clomazone em pré-emergência. A: Diamante Negro; B: Ouro Branco; C: Jalo Precoce; D: BRS Pérola; E: BRS Pontal e F: BRS Radiante. Maringá-PR/ 2012.

Mistura et al. (2008) observaram resultados semelhantes em estudo com o efeito do tratamento de sementes com o dietholate $(1,0 \mathrm{~kg}$ de protetor mais $60 \mathrm{~mL}$ de polímero por $100 \mathrm{~kg}$ de sementes) no índice de velocidade de germinação (IVG) de sementes de arroz cv. BRS Querência. Neste trabalho, os tratamentos foram conduzidos em papel germitest acondicionados em câmara de desenvolvimento biológico (BOD), onde se 
constatou maior IVG em sementes não tratadas com o dietholate, fato este que pode influenciar no estabelecimento da lavoura de arroz. Segundo esses autores, a cobertura das sementes de arroz com este protetor pode ter reduzido a velocidade de absorção de água, a qual é indispensável para desencadear os processos metabólicos e bioquímicos da germinação.

Em relação à altura de plantas aos 7 DAA (Figura 2), o aumento na dose de dietholate no tratamento de sementes na
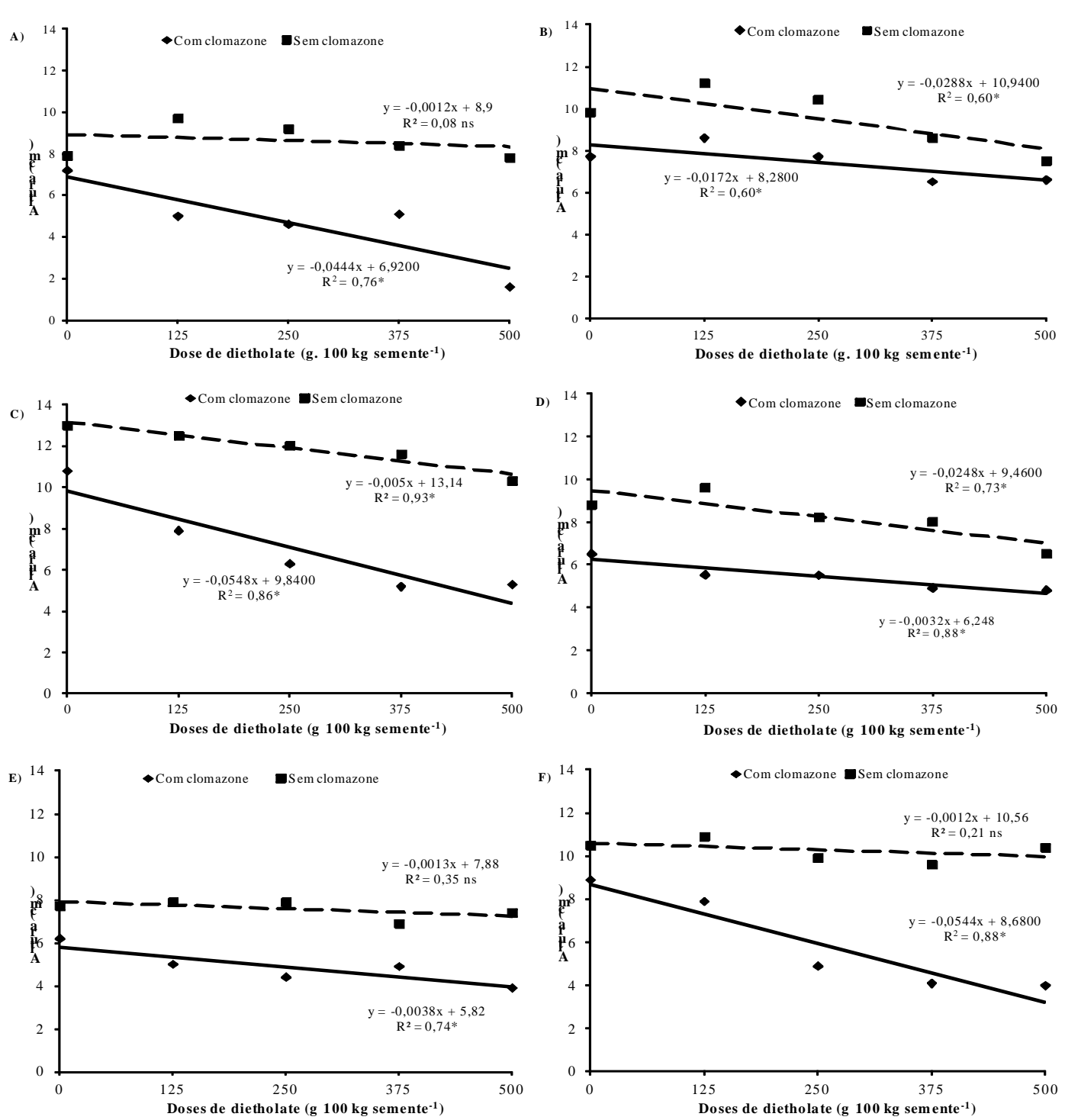

Figura 2. Altura de plantas de feijoeiro aos 7 DAE submetidas a doses crescentes de dietholate, com e sem aplicação de clomazone em pré-emergência. A: Diamante Negro; B: Ouro Branco; C: Jalo Precoce; D: BRS Pérola; E: BRS Pontal e F: BRS Radiante. Maringá-PR/ 2012.

ausência de clomazone não foi suficiente para provocar redução no crescimento das cultivares Diamante Negro, BRS Pontal e BRS Radiante aos 7 DAA (Figura 2). Por outro lado, as demais cultivares apresentaram menor crescimento inicial com o aumento das doses de dietholate, independente do uso do clomazone, o que pode estar associado aos efeitos do composto na velocidade de emergência das plantas mesmo sem a aplicação do herbicida. 
Aos 7 DAE, constatou-se que a aplicação do clomazone em pré-emergência potencializou o efeito fitotóxico do tratamento de sementes com dietholate reduzindo o crescimento de todas as cultivares analisadas, ou seja, a interação destes dois compostos apresentou eficácia limitada no aumento de tolerância da cultura ao clomazone.

$\mathrm{Na}$ avaliação de altura realizada aos 21 DAE (Figura 3), observou-se que somente o aumento na dose de dietholate, sem a aplicação de clomazone, causou a redução do
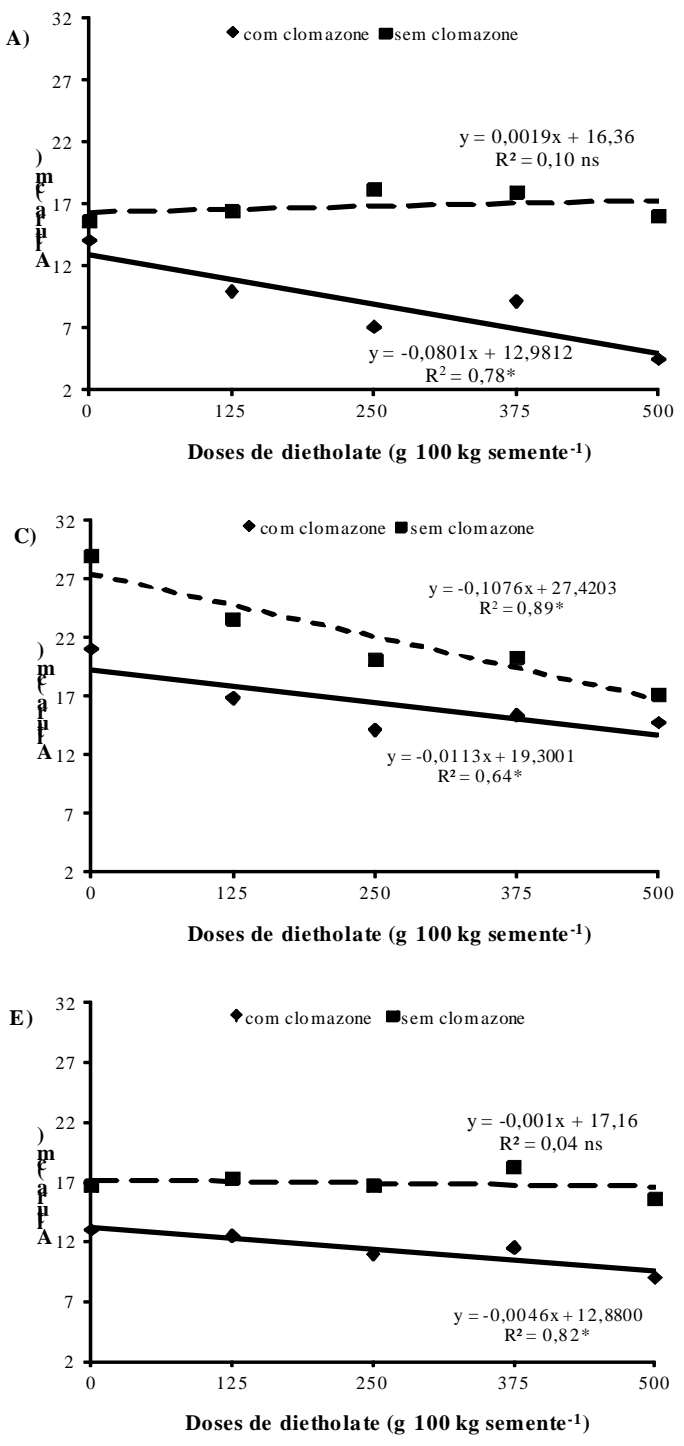

crescimento somente das cultivares Jalo Precoce e BRS Pérola, o que não foi constatado nas outras cultivares.

Ao utilizar o clomazone, o aumento da dose de dietholate afetou o crescimento de todas as cultivares exceto Ouro Branco. Em trabalhos anteriores, Takano et al. (2012) estudando o efeito da aplicação de doses de clomazone em cultivares de feijoeiro, concluíram que a cultivar Jalo Precoce é uma das mais sensíveis ao clomazone.
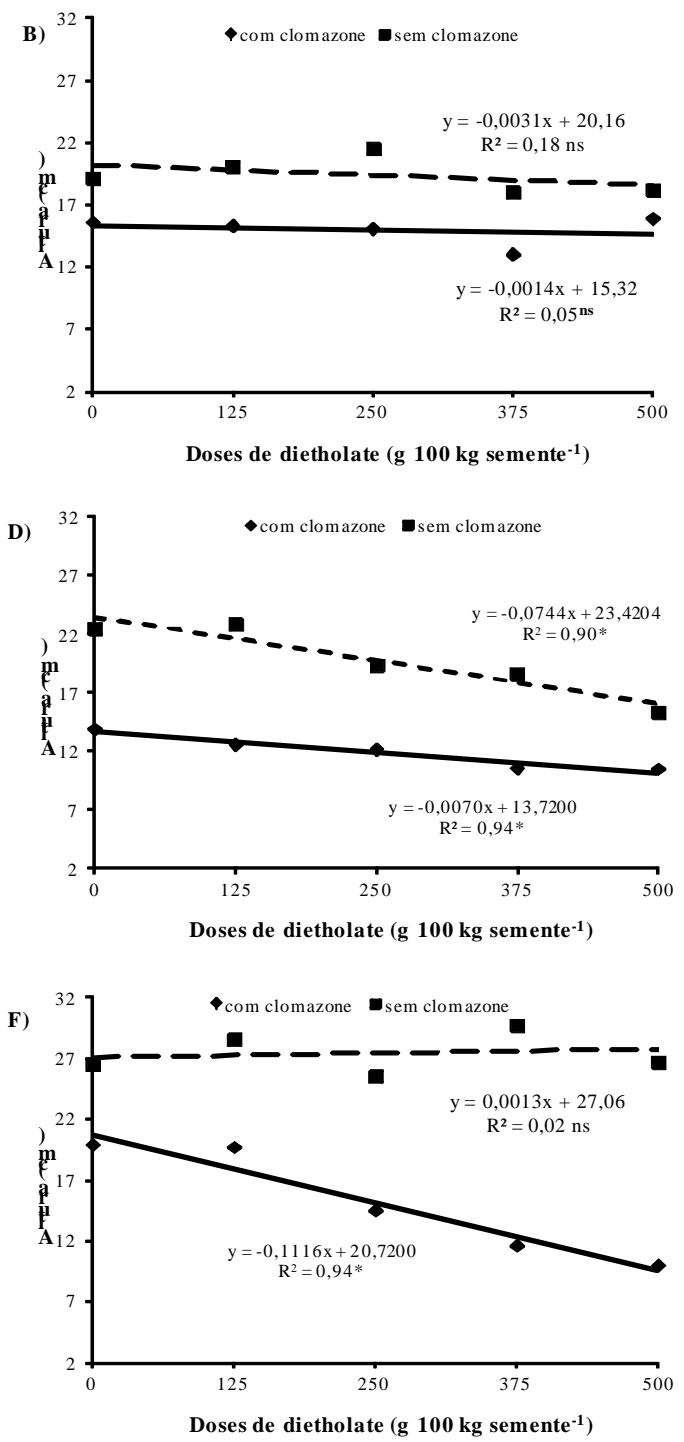

Figura 3. Altura de plantas de feijoeiro aos 21 DAE submetidas a doses crescentes de dietholate, com e sem aplicação de clomazone em pré-emergência. A: Diamante Negro; B: Ouro Branco; C: Jalo Precoce; D: BRS Pérola; E: BRS Pontal e F: BRS Radiante. Maringá-PR/2012. 
Com relação ao índice SPAD das plantas de feijoeiro aos 7 DAE (Figura 4), somente o aumento na dose de dietholate não foi suficiente para reduzi-lo na a maioria das cultivares. Já a utilização de clomazone aliada ao aumento na dose de dietholate, provocou redução no teor de clorofila das cultivares Diamante Negro, Jalo Precoce, BRS Pérola, BRS Pontal e BRS Radiante. O teor de clorofila das plantas é um dos fatores ligados à eficiência fotossintética o qual pode afetar o crescimento e também influenciar na produtividade principalmente quando este teor
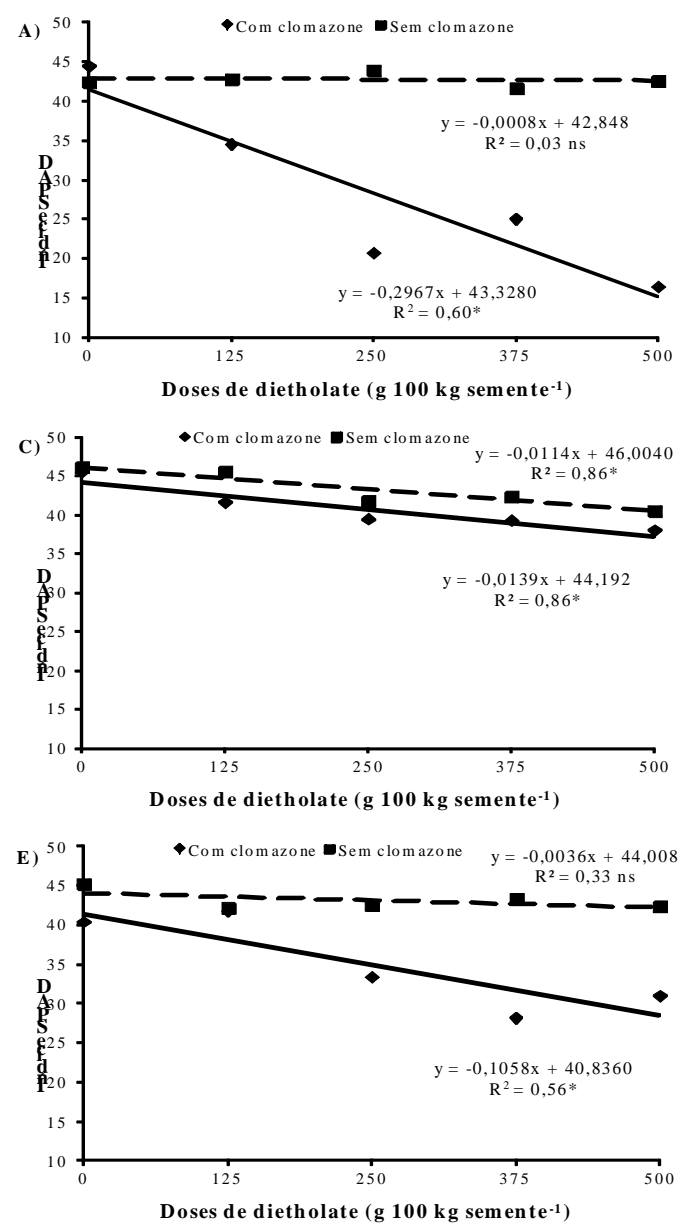

Figura 4. Índice SPAD de plantas de feijoeiro aos 7 DAE submetidas a doses crescentes de dietholate, com e sem aplicação de clomazone em pré-emergência. A: Diamante Negro; B: Ouro Branco; C: Jalo Precoce; D: BRS Pérola; E: BRS Pontal e F: BRS Radiante. Maringá-PR/2012.

$\mathrm{O}$ aumento na dose de dietholate com ou sem a utilização de clomazone em préemergência não afetou significativamente o
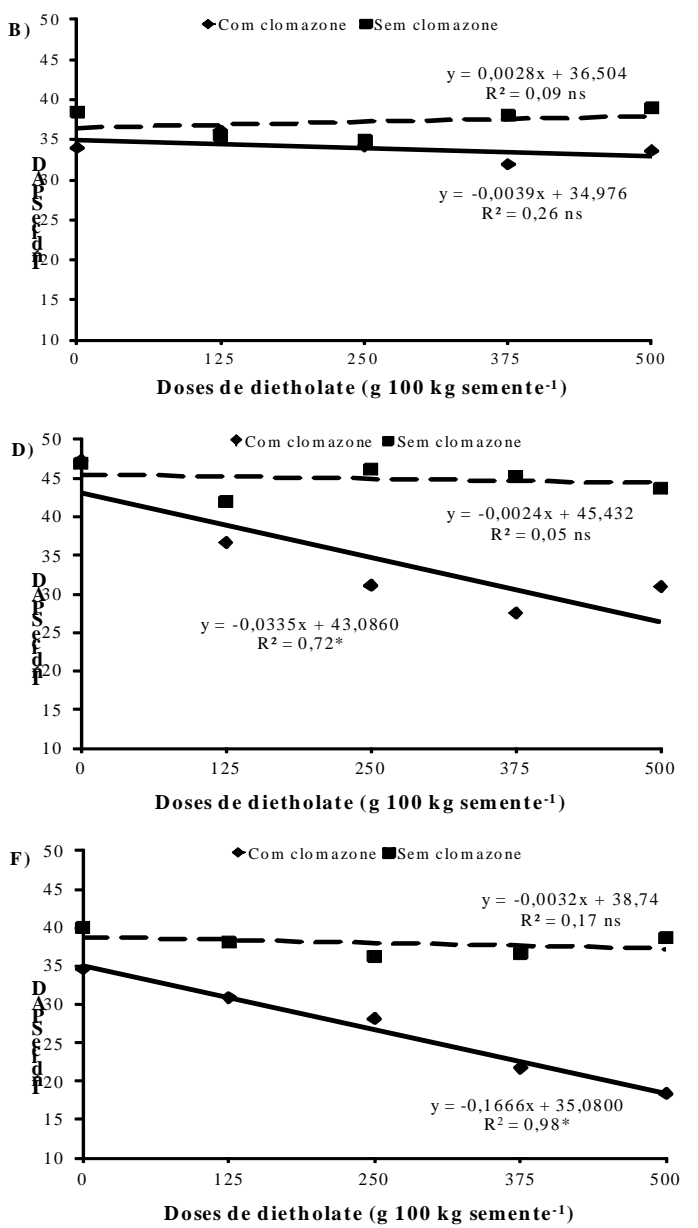

estiver abaixo do nível ótimo para a realização da fotossíntese (Streit et al., 2005).

Em trabalho descrito na literatura, o que ocorre no caso do milho é o oposto. Karam et al. (2003) relatam que mediante a aplicação de $784 \mathrm{~g} \mathrm{ha}^{-1}$ de clomazone, o teor de clorofila foi reduzido em $50 \%$ nas plantas provenientes de sementes não tratadas com dietholate, enquanto que nas plantas provenientes de sementes tratadas com este protetor essa redução foi observada apenas utilizando uma dose maior de clomazone (1740 $\left.\mathrm{g} \mathrm{ha}^{-1}\right)$.

índice SPAD aos 21 DAE, sendo assim os dados não foram apresentados. Nesta data, portanto, as plantas de feijoeiro já 
apresentavam recuperação em relação aos sintomas iniciais de injúria proporcionada pelo clomazone.
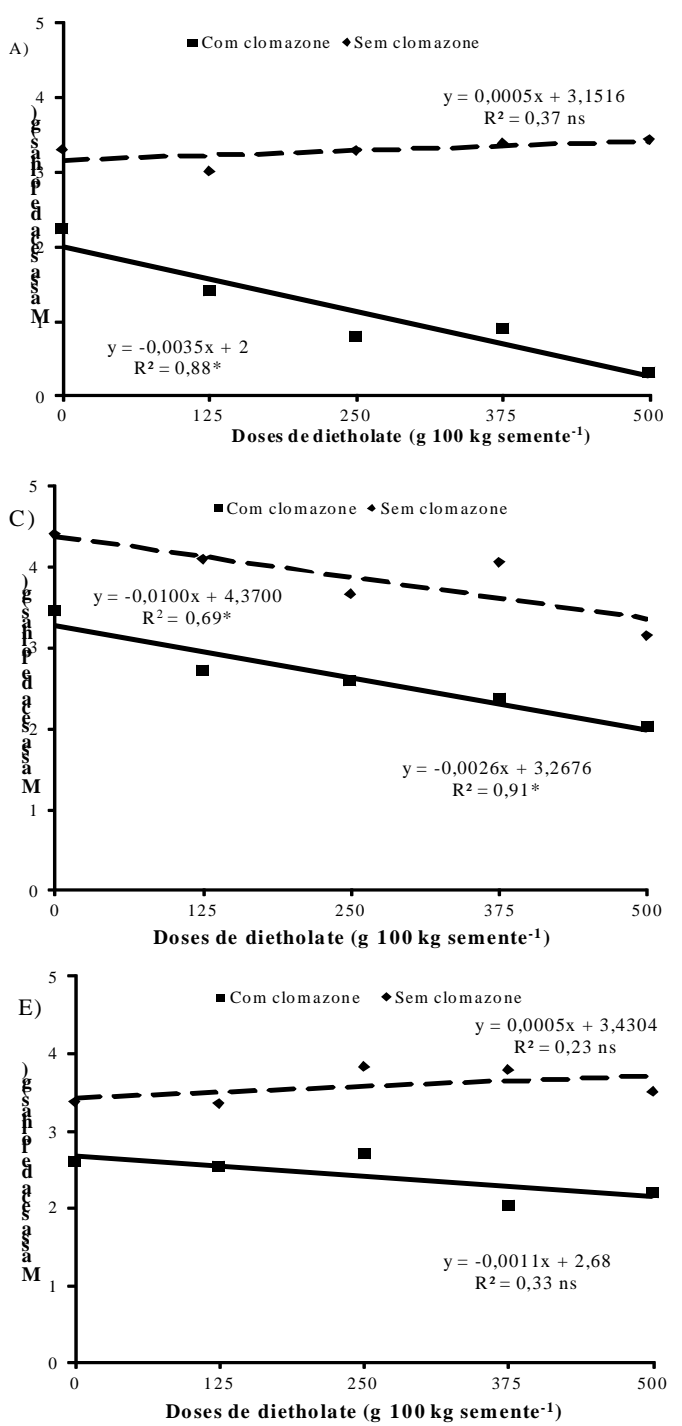

Para a variável massa seca de folhas, foi observado um comportamento distinto entre as cultivares com a variação na dose de dietholate (Figura 5).
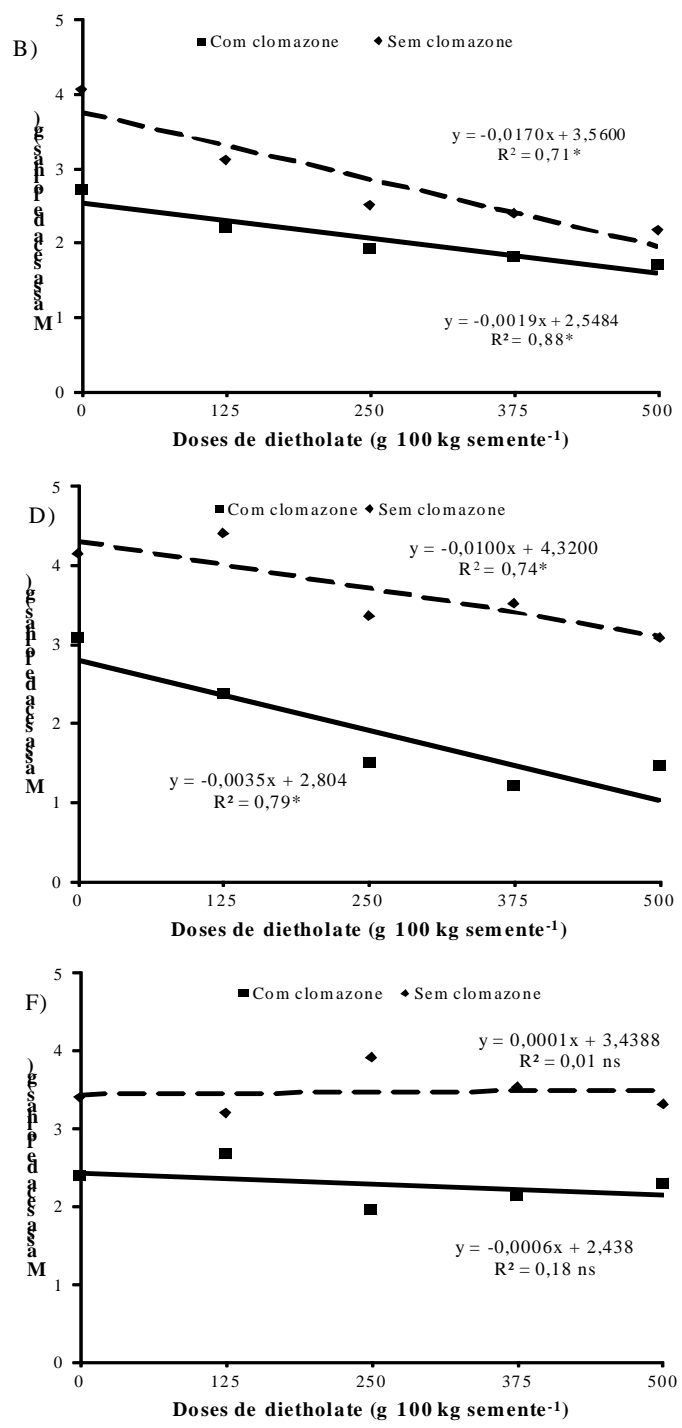

Figura 5. Massa seca das folhas de plantas de feijoeiro aos 21 DAE submetidas a doses crescentes de dietholate, com e sem aplicação de clomazone em pré-emergência. A: Diamante Negro; B: Ouro Branco; C: Jalo Precoce; D: BRS Pérola; E: BRS Pontal e F: BRS Radiante. Maringá-PR/ 2012.

Nas cultivares Diamante Negro, BRS Pontal e BRS Radiante, o aumento na dose de dietholate na ausência de clomazone não causou nenhum problema no acúmulo de massa seca nas folhas. Por outro lado, nas três outras cultivares (Ouro Branco, Jalo Precoce e BRS Pérola) apenas o aumento na dose de dietholate, mesmo na ausência de clomazone, já causou efeitos negativos no acúmulo de massa de folhas. Reduções na massa seca foliar das plantas pode acarretar em menor potencial fotossintético das plantas, fato este que pode se refletir em reduções na produtividade de grãos do feijoeiro, pois segundo Urchei et al. (2000) 
existe uma correlação significativa e positiva entre produção de grãos e acúmulo de massa seca da parte aérea em leguminosas. Tais constatações indicam que, embora existam diferenças importantes entre as cultivares, o dietholate isoladamente apresenta potencial fitotóxico para a cultura do feijoeiro. $\mathrm{Na}$ presença do clomazone, em nenhuma das seis cultivares analisadas, o uso de dietholate, em
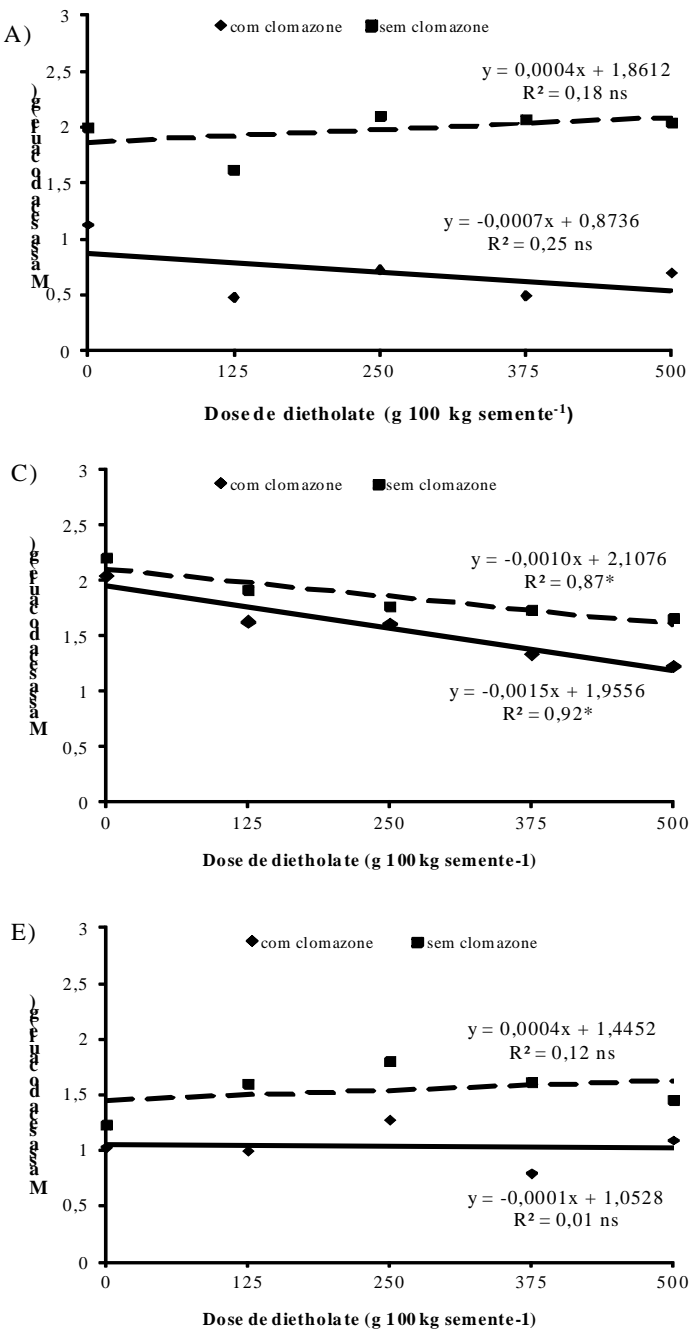

qualquer dose, foi capaz de diminuir o efeito tóxico sobre o feijoeiro em relação ao acúmulo de massa seca nas folhas.

O aumento na dose de dietholate na ausência de clomazone não provocou efeitos negativos no acúmulo de massa seca do caule das cultivares Diamante Negro, Ouro Branco, BRS Pérola e BRS Pontal (Figura 6).
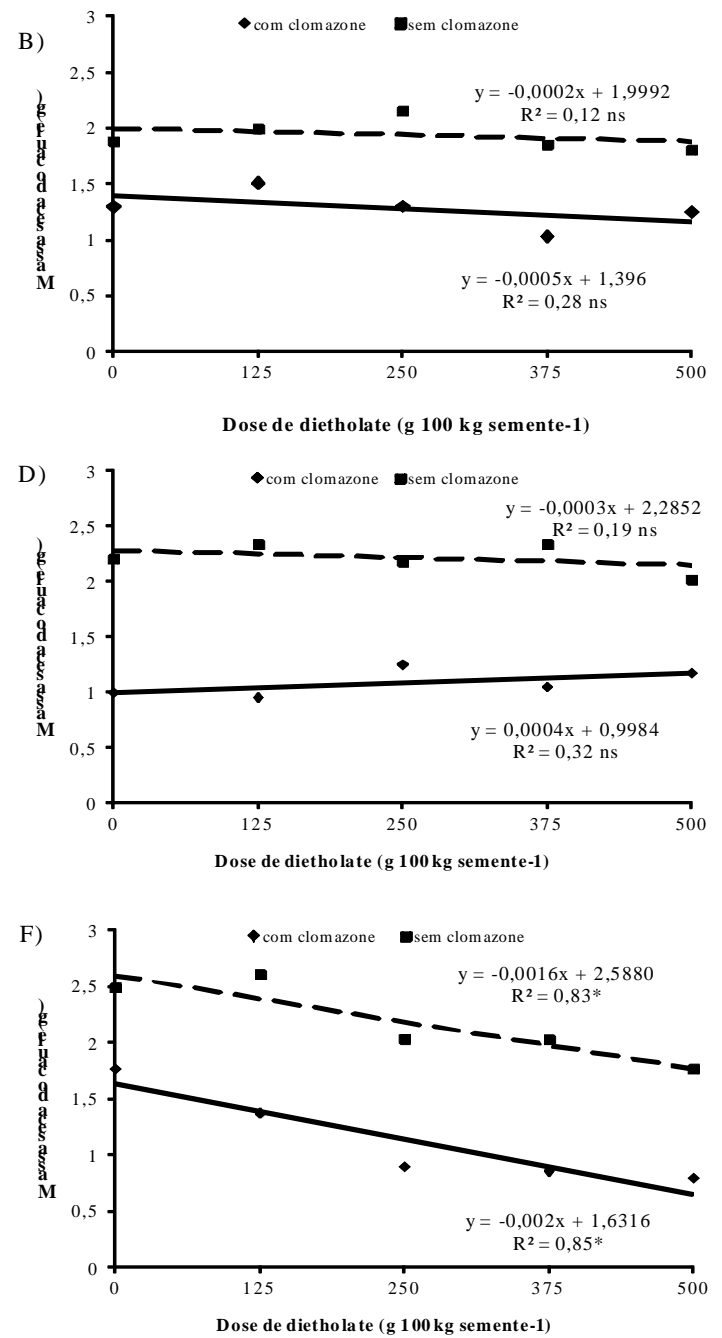

Figura 6. Massa seca do caule de plantas de feijoeiro aos 21 DAE submetidas a doses crescentes de dietholate, com e sem aplicação de clomazone em pré-emergência. A: Diamante Negro; B: Ouro Branco; C: Jalo Precoce; D: BRS Pérola; E: BRS Pontal e F: BRS Radiante. Maringá-PR/ 2012.

As doses mais elevadas de dietholate afetaram esta variável-resposta nas cultivares Jalo Precoce e BRS Radiante. De forma semelhante à massa seca das folhas 0 incremento de dose do protetor junto com clomazone não afetou o acúmulo de massa seca 
do caule em quatro das seis cultivares estudadas (Diamante Negro, Ouro Branco, BRS Pérola e BRS Pontal). No entanto, em nenhuma das cultivares o uso de dietholate proporcionou maior tolerância da cultura ao clomazone.

Segundo Sanchotene et al. (2010), o dietholate confere maior tolerância de plantas de arroz irrigado ao clomazone devido ao bloqueio da ativação deste herbicida por meio da sua não oxidação. Essa oxidação é catalisada pela enzima citocromo P-450 monooxigenase, que tem sua atividade inibida pelo dietholate e por alguns inseticidas do grupo químico dos organofosforados.

No caso do feijoeiro, a utilização de dietholate implica em uma situação inversa, em que a utilização deste composto sem a aplicação de clomazone é, por si só, prejudicial aos parâmetros avaliados neste experimento. As plantas provenientes de sementes tratadas com dietholate e submetidas à aplicação de clomazone em pré-emergência tem esse prejuízo ainda mais evidenciado.

Embora os resultados tenham demonstrado que o tratamento das sementes com dietholate potencializa os efeitos fitotóxicos da aplicação de clomazone nas plantas de feijoeiro, ressalta-se a necessidade de mais estudos, visando avaliar outros parâmetros como o rendimento de grãos e o vigor das sementes tratadas com dietholate.

\section{Conclusões}

Em função dos resultados observados, pode-se inferir que o dietholate não apresenta potencial para proteger as plantas de feijoeiro dos efeitos fitotóxicos do herbicida clomazone, aumentando a sensibilidade das plantas à aplicação do herbicida.

\section{Referências}

COBUCCI, T.; DI STEFANO, J.G.; KLUTHCOUSKI, J. Manejo de plantas daninhas na cultura do feijoeiro em plantio direto. Santo Antônio de Goiás: Embrapa Arroz e Feijão, 1999. 56p. (Embrapa Arroz e Feijão. Circular Técnica, 35).

GALON, L. et al. Seletividade de herbicidas as culturas pelo uso de protetores químicos. Revista Brasileira de Herbicidas, v.10, n.3, p.291-304, 2011.

KARAM, D. et al. Seletividade da cultura do milho ao clomazone por meio do uso de dietholate. Revista Brasileira de Milho e Sorgo, v.2, n.1, p.72-79, 2003.

KOZLOWSKY, L.A. et al. Período crítico de interferência das plantas daninhas na cultura do feijoeiro-comum em sistema de semeadura direta. Planta Daninha, v.20, n.2, p.213-220, 2002.

LIMA, M.G.S. et al. Qualidade fisiológica de sementes de arroz submetidas a estresse salino. Revista Brasileira de Sementes, v.27, n.1, p.54-61, 2005.

MAGUIRE, J.D. Speed of germination-aid in selection and evolution for seedling emergence and vigor. Crop Science, Madison, v.2, n.2, p.176-177, 1962.

MISTURA, C.C. et al. Influência do protetor de sementes dietil fenil fosforotioato sobre plântulas de arroz (Oryza sativa L.). Revista Brasileira de Agrociência, v.14, n.2, p.231238, 2008.

OLIVEIRA JR.; R.S.; INOUE, M.H. Seletividade de herbicidas para culturas e plantas daninhas. In: OLIVEIRA JR.; R.S.;CONSTANTIN, J.; INOUE, M.H. (Ed.). Biologia e manejo de plantas daninhas. Curitiba, PR: Omnipax, 2011. p.243-262.

SANCHOTENE, D.M. et al. Phorate e dietholate protegem o arroz da fitotoxicidade do clomazone em doses elevadas. Planta Daninha, v.28, n.4, p.909-912, 2010.

STREIT, N.M. et. al. As clorofilas. Ciência Rural, v.35, n.3, p.748-755, 2005. 
TAKANO, H.K. et al. Potential use of clomazone on common bean cultivars. Revista Brasileira de Herbicidas. v.11, n.2, p.187194, 2012.

URCHEI, M.A.; RODRIGUES, J.D.; STONE, L.F. Análise de crescimento de duas cultivares de feijoeiro sob irrigação, em plantio direto e preparo convencional. Pesquisa Agropecuária Brasileira, v.35, n.3, p.497-506, 2000. 